\title{
Characterization of human spermatogonial stem cell markers in fetal, pediatric, and adult testicular tissues
}

\author{
Eran Altman ${ }^{1,2}$, Pamela Yango ${ }^{1}$, Radwa Moustafa ${ }^{1}$, James F Smith ${ }^{3}$, Peter C Klatsky ${ }^{4}$ \\ and Nam D Tran ${ }^{1}$ \\ ${ }^{1}$ Department of Obstetrics, Gynecology and Reproductive Sciences, University of California, San Francisco, \\ San Francisco, California 94143, USA, ${ }^{2}$ Helen Schneider Hospital for Women, Rabin Medical Center, Petah Tikva, \\ Israel, ${ }^{3}$ Department of Urology, University of California, San Francisco, San Francisco, California, USA and \\ ${ }^{4}$ Department of Obstetrics and Gynecology, Albert Einstein University, Bronx, New York, USA \\ Correspondence should be addressed to N D Tran; Email: trann@obgyn.ucsf.edu
}

\begin{abstract}
Autologous spermatogonial stem cell (SSC) transplantation is a potential therapeutic modality for patients with azoospermia following cancer treatment. For this promise to be realized, definitive membrane markers of prepubertal and adult human SSCs must be characterized in order to permit SSC isolation and subsequent expansion. This study further characterizes the markers of male gonocytes, prespermatogonia, and SSCs in humans. Human fetal, prepubertal, and adult testicular tissues were analyzed by confocal microscopy, fluorescence-activated cell sorting, and qRT-PCR for the expression of unique germ cell membrane markers. During male fetal development, THY1 and KIT (C-Kit) are transient markers of gonocytes but not in prespermatogonia and post-natal SSCs. Although KIT expression is detected in gonocytes, THY1 expression is also detected in the somatic component of the fetal testes in addition to gonocytes. In the third trimester of gestation, THY1 expression shifts exclusively to the somatic cells of the testes where it continues to be detected only in the somatic cells postnatally. In contrast, SSEA4 expression was only detected in the gonocytes, prespermatogonia, SSCs, and Sertoli cells of the fetal and prepubertal testes. After puberty, SSEA4 expression can only be detected in primitive spermatogonia. Thus, although THY1 and KIT are transient markers of gonocytes, SSEA4 is the only common membrane marker of gonocytes, prespermatogonia, and SSCs from fetal through adult human development. This finding is essential for the isolation of prepubertal and adult SSCs, which may someday permit fertility preservation and reversal of azoospermia following cancer treatment.

Reproduction (2014) 148 417-427
\end{abstract}

\section{Introduction}

The isolation, expansion, and successful reconstitution of spermatogenesis after spermatogonial stem cell (SSC) transplantation in the murine model have opened new doors for potential human therapeutic applications such as fertility treatments and preservation (Brinster \& Avarbock 1994, Brinster \& Zimmermann 1994, Kanatsu-Shinohara et al. 2003). Unfortunately, 20 years after the first reports of successful testicular germ cell transplantations in mice, progress in human SSC research has been limited mainly due to the scarcity of available human testicular tissues for research and the lack of an effective in vivo model fully capable of supporting human spermatogenesis (Brinster \& Avarbock 1994, Brinster \& Zimmermann 1994, Dym et al. 2009, Cheng \& Mruk 2010).

Successful in vitro expansion of prepubertal and adult human SSCs, capable of engrafting in mouse seminiferous tubules in a human murine xenograft model, had been reported using testicular cells from digested seminiferous tubules (Sadri-Ardekani et al. 2009, 2011, Liu et al. 2011, Mirzapour et al. 2012). In addition, these in vitro-derived human SSCs were shown to possess pluripotent properties similar to embryonic stem cells (Conrad et al. 2008, Golestaneh et al. 2009, Kossack et al. 2009, Mizrak et al. 2010). However, these in vitroexpanded pluripotent human SSCs, capable of multilineage differentiation, have been questioned as recent studies demonstrated that these cells exhibited mesenchymal rather than germ cell properties highlighting the need for further characterization of the SSC population (Ko et al. 2011, Tapia et al. 2011, Chikhovskaya et al. 2012). Most previous human SSC studies used a mixed population of testicular cells (somatic and germ cells combined) from enzymatically digested seminiferous tubules for culture, expansion, and transplantation. Thus, the precise identity of the primitive, pluripotent germ cells within the testicular cell population capable of expansion and engraftment is uncertain.

In order to permit fertility preservation using cryopreservation and subsequent transplantation of autologous 
SSCs in prepubertal boys undergoing sterilizing oncologic treatments, it is vital to develop the ability to isolate SSCs capable of engraftment through the use of unique membrane markers, thus eliminating the risks of malignant cell contamination from the testicular cell population (Fujita et al. 2005, 2006, Hermann et al. 2011, Dovey et al. 2013). While definitive markers of SSCs have been identified in mice, unique membrane markers of primate and human SSCs have yet to be fully characterized (Ebata et al. 2005, Gashaw et al. 2007, Seandel et al. 2007, Conrad et al. 2008, Muller et al. 2008, Dym et al. 2009, Grisanti et al. 2009, Maki et al. 2009, Wu et al. 2009, He et al. 2010, Izadyar et al. 2011, Eildermann et al. 2012, Dovey et al. 2013, Kossack et al. 2013). Although THY1, GFR $\alpha 1 R$, GPR125, EPCAM, and SSEA4 have been reported to be unique membrane markers of adult human SSCs, many of these markers (GFR $\alpha 1 \mathrm{R}$, GPR125, and EPCAM) are also expressed in adult testicular stromal cells, limiting their potential use as markers for SSC isolation (Conrad et al. 2008, Wu et al. 2009, He et al. 2010, Izadyar et al. 2011, Dovey et al. 2013). Although primary adult human testicular cells expressing SSEA4 were shown to engraft in mouse seminiferous tubules, SSEA4 expression was not detected in human SSCs by others (Izadyar et al. 2011, Dovey et al. 2013). Thus, there is a lack of consensus agreement on the unique membrane markers of human SSCs.

A logical approach to identify the unique membrane markers of human SSCs is to study human male germ cells during development (gonocytes and prespermatogonia), before the onset of spermatogenesis and follow them through puberty (spermatogonia) and adulthood. If a unique membrane marker of primitive germ cells was present through all stages of development, it may serve as an important marker of SSCs. Recent studies have reported two distinct populations of primitive germ cells, gonocytes and prespermatogonia, within the male fetal testes during the first two trimesters of gestation (Pauls et al. 2006, Anderson et al. 2007, Gkountela et al. 2012, Jorgensen et al. 2012). OCT4A and KIT (C-Kit) were expressed in gonocytes during the late-first and early-second trimesters; however, expression of VASA was not found in these gonocytes (Anderson et al. 2007, Gkountela et al. 2012). During the second trimester, prespermatogonia began to appear in the testes, presumably from the differentiation of gonocytes (Gkountela et al. 2012). While the prespermatogonia expressed VASA, they no longer expressed OCT4A and KIT (Pauls et al. 2006, Anderson et al. 2007, Gkountela et al. 2012). Therefore, KIT was the only membrane marker in fetal gonocytes, but such an identifying marker unique to prespermatogonia and spermatogonia remains to be investigated.

Thus, we aim to characterize the expression of human primitive germ cell membrane markers from fetal development (gonocytes and prespermatogonia) through adulthood (spermatogonia and SSCs).

\section{Materials and methods}

\section{Testicular tissues}

All tissues were obtained after informed consent in accordance with the study protocol approved by the University of California, San Francisco (UCSF) IRB. Human fetal testes (13-24 weeks of gestation) were collected following elective terminations of pregnancy, excluding cases with fetal anomalies $(n=33)$. Gestational age was determined by last menstrual cycle and confirmed with ultrasound and subsequent foot length measurement. Autopsied prepubertal testicular tissues were obtained from deceased subjects, whose death was not related to disorders of their reproductive system $(n=3)$. Adult testicular biopsy samples were collected from patients $(n=3)$ with normal spermatogenesis, who underwent testicular spermatocelectomy, vasovasostomy, and testicular excisional sperm extraction due to anejaculation.

\section{Confocal microscopy}

The tissues were fixed in $4 \%$ paraformaldehyde, embedded in optimal cutting temperature compound (Sakura Finetek, Torrance, CA, USA), and cryosectioned at $5 \mu \mathrm{m}$. The sections were permeabilized with $0.1 \%$ Triton-X-100 PBS (SigmaAldrich), blocked in 5\% BSA-PBS, and incubated overnight at $4{ }^{\circ} \mathrm{C}$ with the following antibodies: goat anti-VASA (R\&D Systems-AF2030 at 1:100 dilution, Minneapolis, MN, USA), anti-THY1 (BD Biosciences-559869 at 1:50, San Jose, CA, USA, and R\&D Systems-AF206 at 1:40), rabbit anti-WT1 (Santa Cruz Biotechnology-SC-192 at 1:75, Dallas, TX, USA), antiOCT4A (Santa Cruz Biotechnology SC-9081 at 1:75, and SC-8628 at 1:75), mouse anti-SSEA4 (BD Biosciences-560308 at 1:50), anti-C-Kit (Santa Cruz Biotechnology SC-5535 at 1:50 and M14 at 1:50), mouse anti-SSEA1 (R\&D Systems-FAB2155A at 1:50), mouse anti-TRA-1-81 (BD Biosciences-560885 at 1:50), mouse anti-TRA-1-60 (BD Biosciences-560071 at 1:50), goat anti- GFR $\alpha 1 R$ (R\&D Systems-AF714 at 1:50), rabbit anti-MAGEA4 (Abcam, Cambridge, MA, USA, ab76177 at 1:50), rat anti-SSEA3 (Abcam ab16286 at 1:100), and rabbit anti-GPR125 (Abcam-ab51705 at 1:50). Primary speciesspecific isotypes were used for controls. Donkey anti-goat Alexa 488 and 555, donkey anti-sheep Alexa 555, donkey antirabbit Alexa 555 and 594, donkey anti-mouse Alexa 488, 555 and 594 (BD Biosciences) were applied accordingly the following day at 1:200-1:500 dilutions at room temperature for $1 \mathrm{~h}$. The images were captured using a Leica SP5 AOBS confocal microscope (Leica Microsystems, Inc., Buffalo Grove, IL, USA) and analyzed using ImageJ v1.6 (rsbweb.nih.gov).

\section{Testicular cell isolation and fluorescence-activated cell sorting}

The tissues were subjected to a two-step enzymatic digestion with collagenase IV ( $1 \mathrm{mg} / \mathrm{ml}$; Sigma-Aldrich) in DMEM/F12 + Glutamax (Invitrogen) for $20 \mathrm{~min}$ at $37^{\circ} \mathrm{C}$, followed by trypsin EDTA $0.25 \%$ (UCSF Cell Culture Facility) and DNase I $(50 \mu \mathrm{g} / \mathrm{ml}$; Sigma-Aldrich) for $20 \mathrm{~min}$, and filtered through a $70 \mu \mathrm{m}$ cell strainer. The cells were incubated with the following antibodies: anti-SSEA4 FITC (BD-560308), anti-THY1 APC 
(BD-559869), anti-C-KIT PE (R\&D-FAB332P), anti-TRA1-81 PE (BD-560885), and anti-SSEA1 APC (R\&D-FAB2155A), in $1 \%$ BSA for $30 \mathrm{~min}$ at $37{ }^{\circ} \mathrm{C}$. Cell sorting was carried out on a BD fluorescence-activated cell sorting (FACS) Aria Flow Cytometer and analyzed using Flowjo v9.6 (Flowjo, Ashland, OR, USA): 50 000-200 000 events were acquired for analyses.

\section{Molecular analyses}

Subpopulations of testicular cells were sorted directly into RNA lysis buffer. Total RNA was isolated using the RNeasy Micro Kit (QIAGEN) and cDNA was synthesized using qScript cDNA Super Mix (Quanta Biosciences, Gaithersburg, MD, USA). Each qPCR amplification was carried out in triplicate at 250 cells/reaction using FastStart Universal SYBR Green Master Mix with ROX (Roche) and Applied Biosystem 7500 Real-time PCR System. The list of primers and sequences is provided in Supplementary Table, see section on supplementary data given at the end of this article. Gene expression was analyzed using the $2^{-\left(\Delta C_{\mathrm{T}}\right)}$ and $2^{-\left(\Delta \Delta C_{\mathrm{T}}\right)}$ methods. ANOVA were used for statistical analyses.

\section{Results}

\section{Male fetal testes contain two populations of germ cells defined by the relative expression of VASA}

In addition to published membrane markers of human and mouse SSCs (GPR125, GFR $\alpha 1 R$, SSEA1, SSEA4, KIT, and THY1), expression of embryonic stem cell membrane markers (TRA1-60 and TRA1-81) was also evaluated in both gonocytes and prespermatogonia. The expression of GPR125, GFR $\alpha 1 R$, TRA160, TRA1-81, and SSEA1 was not detected in either early- or latesecond trimester testes by confocal microscopy and flow cytometry (data not shown). The germ cells expressing VASA were first detected at 13 weeks of gestation (the earliest time point examined) and continued to increase in number throughout gestation. At 13 weeks of gestation, two populations of germ cells were identified based on relative expression of VASA, VASA dim $\left(V_{D S A}\right)$, and VASA bright $\left(\mathrm{VASA}_{\mathrm{B}}\right)$, (Fig. $\left.1 \mathrm{~A}\right)$. Moreover, the number of $V_{A S A_{B}}$ cells increased with advancing gestation. At gestational week 13 and 24, the ratio of $\mathrm{VASA}_{\mathrm{D}} / \mathrm{VASA}_{\mathrm{B}}$ germ cells decreased from $3 / 2$ (Fig. 1A) to $1 / 3$ when all VASA ${ }^{+}$cells from ten cords were counted (Fig. 1B), respectively, suggesting that the $V_{A S A_{B}}$ population represent the prespermatogonia population as the number of VASA $A_{B}$ cells increased with gestation. In contrast, the $V A S A_{D}$ population may represent the rare gonocyte population. Both $V_{A S A}$ and $V_{D A S A}$ cells co-expressed MAGEA4 further confirming that they are indeed primitive germ cells (Fig. 1C). Given the previous finding of OCT4A expression in VASA-negative gonocytes, we evaluated VASA $A_{D}$ expression in these cells. Rare OCT4A-positive cells were detected only in cells expressing low levels of VASA (Fig. 1D), demonstrating that VASA ${ }_{D}$ cells are indeed gonocytes.

\section{SSEA4 is a common membrane marker for gonocytes, prespermatogonia, and Sertoli cells}

All of the cells within the seminiferous cord, during the second and third trimesters, expressed SSEA4 (Fig. 1E). Both VASA ${ }_{D}$ and $V_{A S A}$ cells expressed SSEA4 at similar levels, indicating SSEA4 to be a common marker for both gonocytes and prespermatogonia. However, SSEA4 expression was also detected in the remaining VASAnegative cells making up the cord. WT1 expression was then evaluated to determine whether these SSEA4 ${ }^{+}$/ $\mathrm{VASA}^{-}$cells were Sertoli cells. WT1 was expressed exclusively in all SSEA $4^{+}{ }^{N A S A}{ }^{-}$cells (Fig. $1 \mathrm{~F}$ ), confirming that all the non-germ cells expressing SSEA $4^{+}$in the seminiferous cords were Sertoli cells.

\section{Gonocytes transiently express KIT and THY1}

KIT and THY1 expression in gonocytes, prespermatogonia, and Sertoli cells was also evaluated. Gonocytes expressing OCT4A were found to co-express KIT, in addition to $\mathrm{VASA}_{\mathrm{D}}$ (Fig. 2A). In contrast to SSEA4, the majority of THY1 expression was detected on cells outside of the seminiferous cords with the exception of a few cell clusters within the cords during the second trimester (Fig. 2B). Within the seminiferous cord, $\mathrm{THY}^{+}{ }^{+}$ cells were arranged in small clusters of 3-6 cells and expressed low levels of VASA (VASA ${ }_{D}$ ) (Fig. 2C). In contrast, VASA $\mathrm{B}_{\mathrm{B}}$ cells never expressed THY1. Furthermore, WT1 expression was never detected in $\mathrm{THY} 1^{+}$cells, indicating that SSEA $4{ }^{+} / \mathrm{THY}{ }^{+}$cells are primitive gonocytes (Fig. 2C). Within the cords, THY1 ${ }^{+}$ cells co-expressed OCT4A further confirming that SSEA4, THY1, and KIT are membrane markers on gonocytes (Fig. 2D).

To confirm that SSEA $4^{+} / \mathrm{THY} 1^{+}$cells were in fact gonocytes, male fetal testes were digested, FACS sorted, and individually analyzed for SSEA4 expression. SSEA4 ${ }^{+}$ and SSEA4 ${ }^{-}$cells were individually assessed for THY1 expression (Fig. 3A). At 19 weeks of gestation, $\sim 10 \%$ of the total SSEA $4{ }^{+}$cells were THY ${ }^{+}{ }^{+}$(gonocytes; Fig. $3 \mathrm{~A}$ ). The remaining $\sim 90 \%$ of the SSEA $4^{+}$cells were THY 1 negative (prespermatogonia and Sertoli cells). In contrast, $>90 \%$ of SSEA $4{ }^{-}$cells expressed THY 1 . Similar to confocal microscopy observations that the number of $V A S A_{D}$ cells decreased with advancing gestation (Fig. 1A and $\mathrm{B}$ ), the number of gonocytes (SSEA $4^{+} / \mathrm{THY} 1^{+}$) decreased to $\sim 6 \%$ at 23 weeks of gestation (Fig. 3A).

These findings were confirmed at the molecular level by qPCR analysis. SSEA $4^{+} / \mathrm{THY}^{+}{ }^{+}$(gonocytes) expressed high levels of VASA (139-fold) and OCT4A (13-fold; Fig. 3B). Although, VASA and OCT4A were also detected in SSEA4 ${ }^{+} / \mathrm{THY}^{-}$(prespermatogonia and Sertoli cells), their levels were significantly lower than the pure gonocyte population, confirming that this population contains both prespermatogonia and Sertoli cells (Fig. 3B). Both $A M H$ and SOX9 were more highly 
A
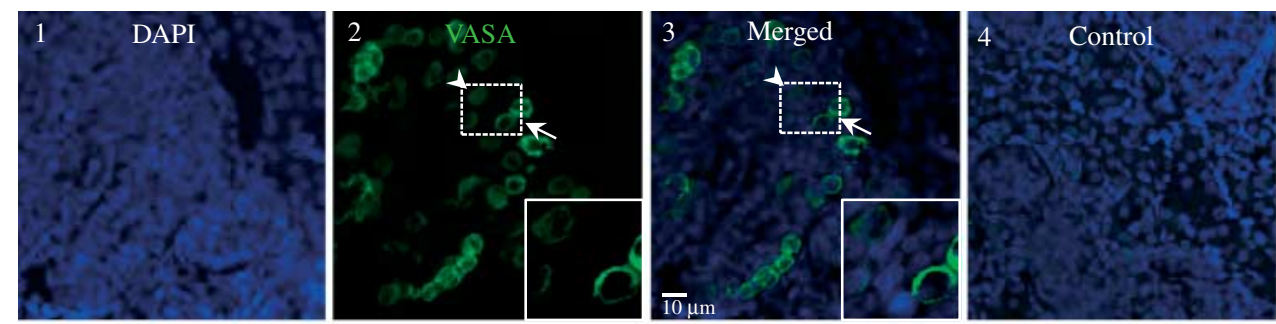

B
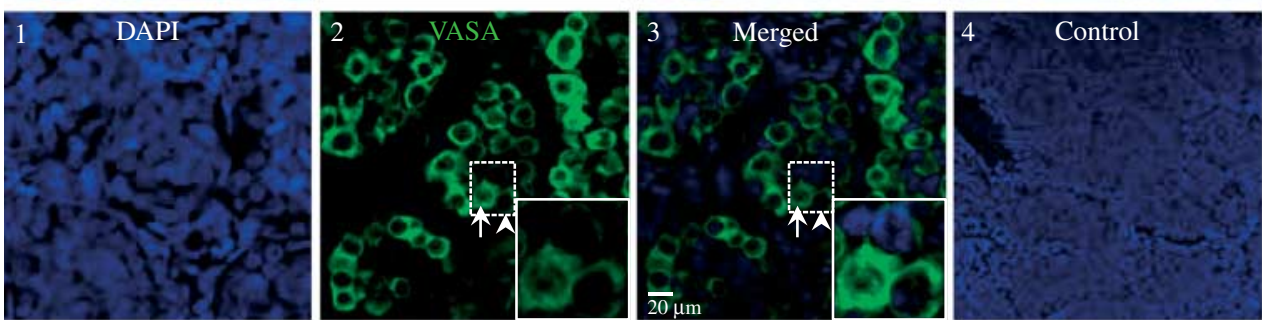

C
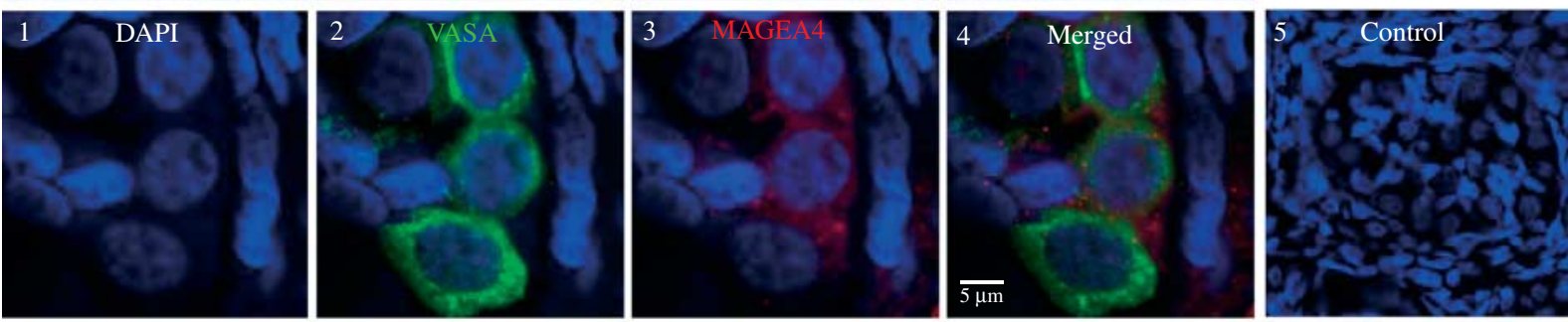

$\mathrm{D}$
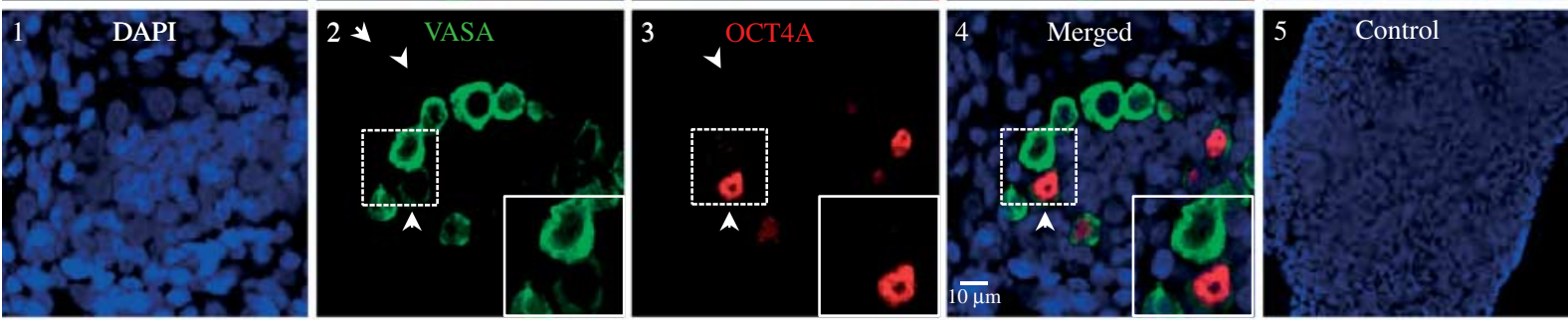

$\mathrm{E}$
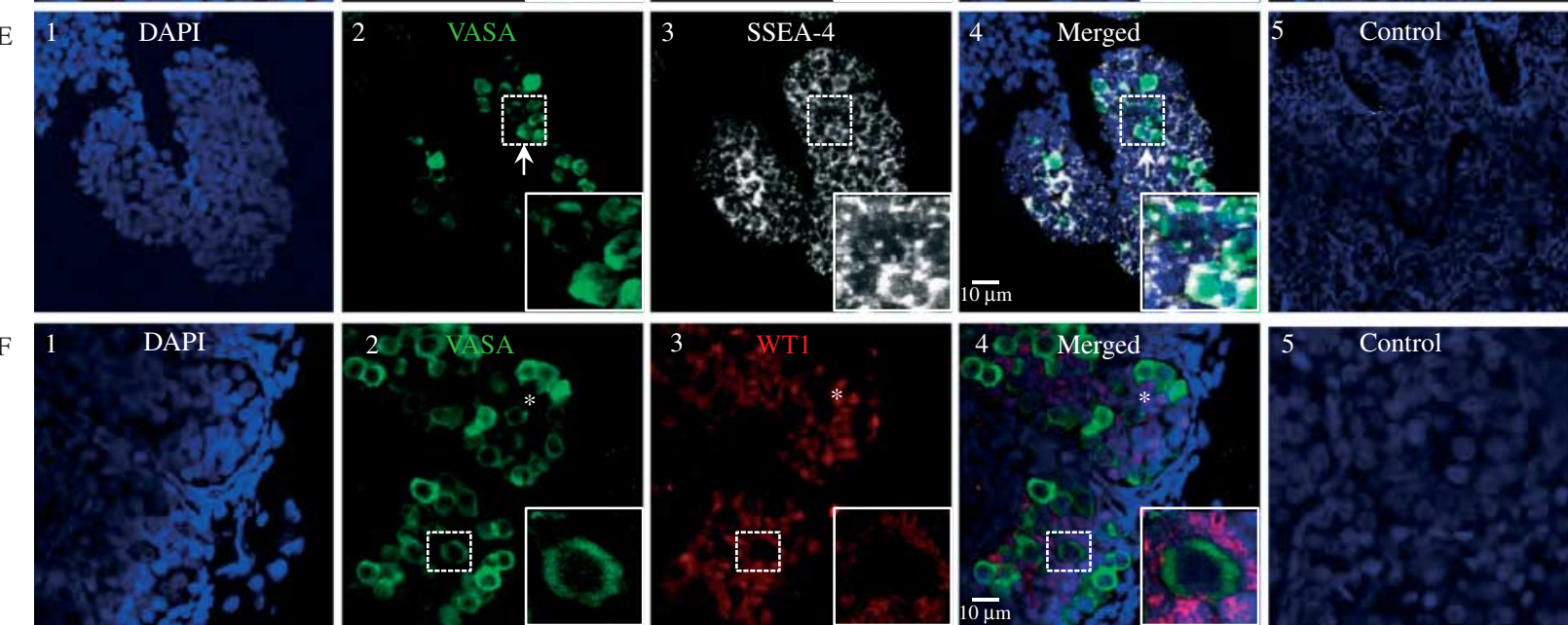

Figure 1 The dynamic of VASA, OCT4A, and SSEA4 expression in male testes at 13-24 weeks of gestation. (A) Two populations of germ cells were observed based on relative expression of VASA, VASA dim $\left(V A S A_{D}\right)$ vs VASA bright $\left(V A S A_{B}\right)$, shown here at 13 weeks of gestation. Ratio of $V_{A S A} / V A S A_{B}$ germ cells $\sim 3 / 2$. (B) The ratio of $V A S A_{D} / V A S A_{B}$ germ cells $(\sim 1 / 3)$ decreased with advancing gestation, shown here at 24 weeks of gestation. (C) All VASA ${ }^{+}$cells co-expressed MAGEA4, shown at 20 weeks of gestation. (D) Only VASA $\mathrm{D}_{\mathrm{D}}$ germ cells expressed OCT4A during the second trimester, shown here at 21 weeks of gestation. (E) Both VASA ${ }_{D}$ and VASA $A_{B}$ germ cells expressed similar levels of SSEA4 shown at 20 weeks of gestation. (E and F) Fetal Sertoli cells also expressed SSEA4. Arrow head, arrow, and asterisk indicate VASA $\mathrm{V}_{d}$ VASA $\mathrm{A}_{\mathrm{b}}$, and Sertoli cells respectively. Ratio of $\mathrm{VASA}_{\mathrm{D}} / \mathrm{VASA}_{\mathrm{B}}$ cells was determined by counting all VASA ${ }^{+}$cells from ten cords. Donkey anti-goat Alexa 488 (VASA), anti-mouse Alexa 594 (MAGEA4), anti-rabbit Alexa 594 (OCT4A, WT1), and anti-mouse Alexa 555 (SSEA4) were used. *indicates somatic cells outside of the cords. 

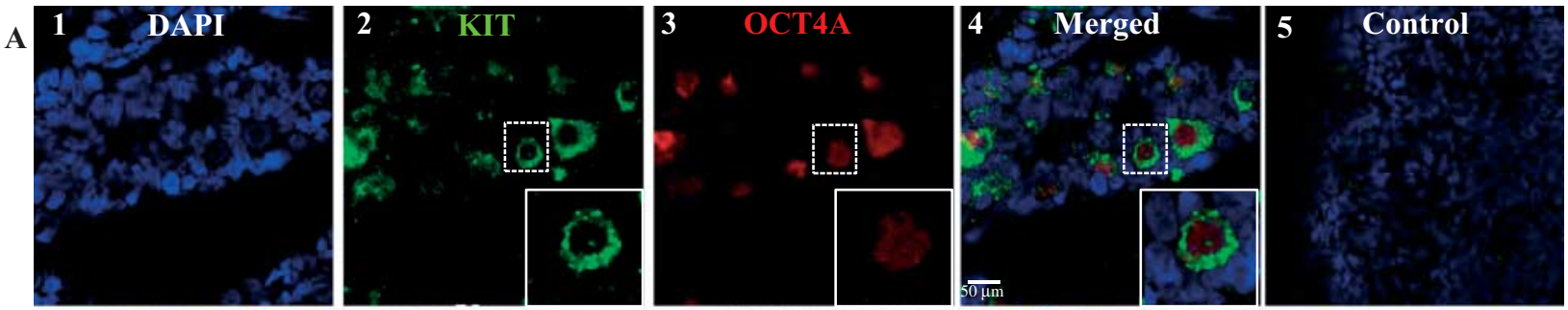

B
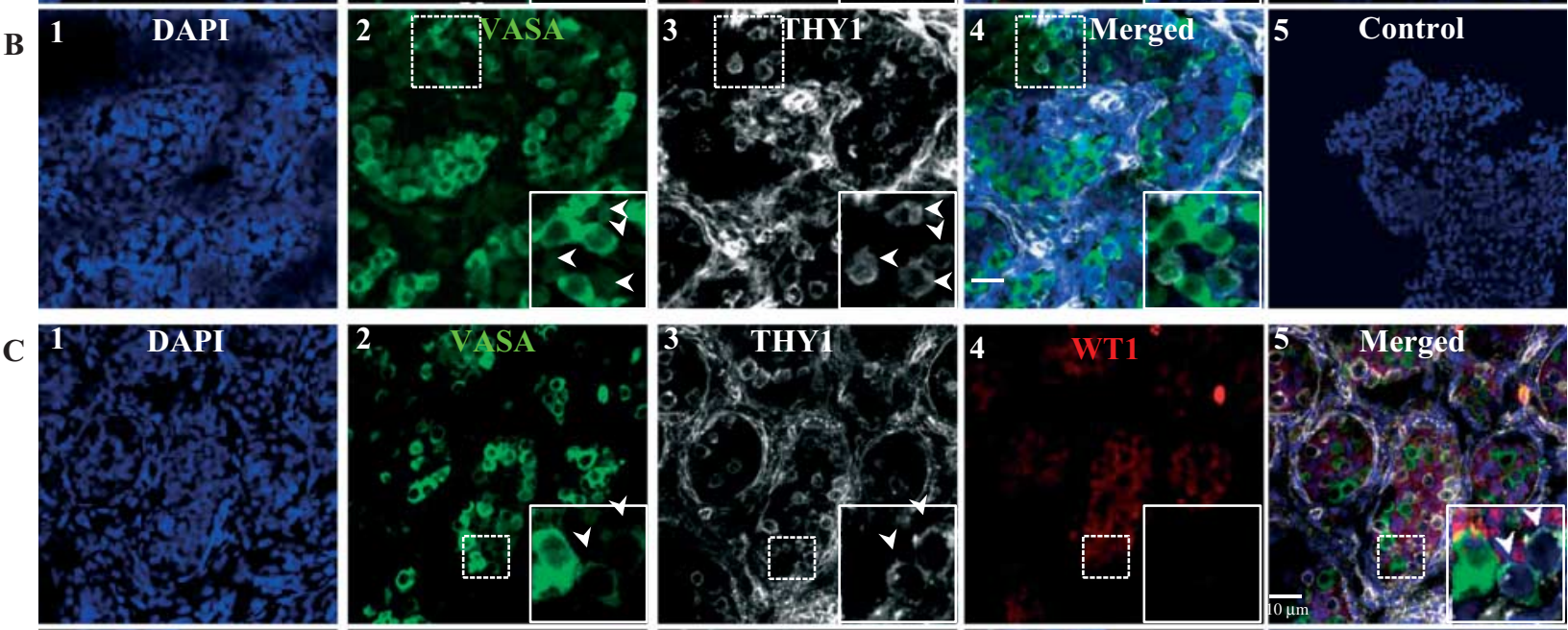

D
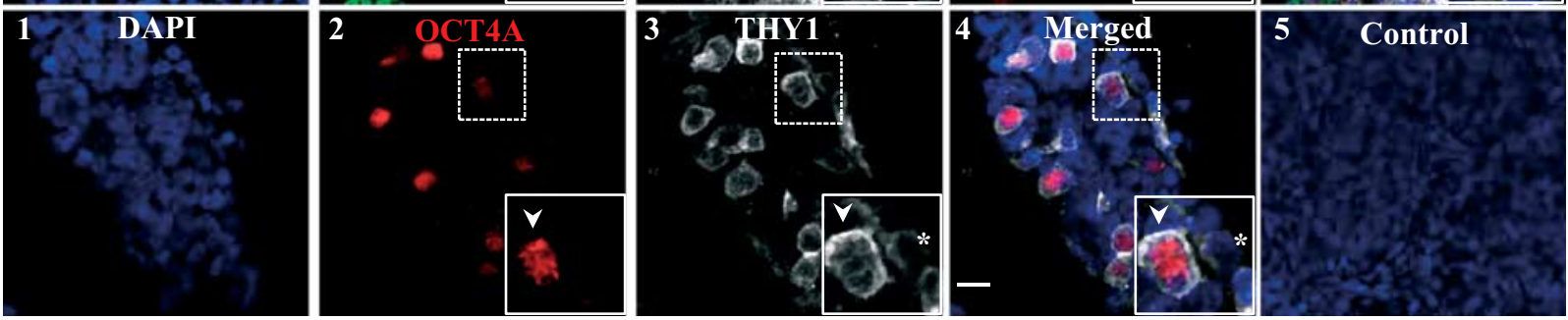

Figure 2 Extracellular membrane markers of fetal male gonocytes. Gonocytes also co-expressed KIT (A) and THY1 (B), shown at 15 and 19 weeks of gestation respectively. While SSEA4 ${ }^{+}$is a general marker for all germ and Sertoli cells in the fetal testes, THY1 expression within the SSEA4 population was restricted only to gonocytes that expressed low level of VASA (VASA ${ }_{D}$ ) (C) and OCT4A (D), shown at 21 and 18 weeks of gestation respectively. Arrow heads indicate VASA ${ }_{D}$ cells (gonocytes). Donkey anti-goat Alexa 488 (VASA), anti-mouse Alexa 488 KIT, anti-rabbit Alexa 594 (OCT4A), and anti-mouse Alexa 555 (THY1) were used. *Indicates somatic cells outside of the cords.

expressed in the SSEA4 $4^{+} / \mathrm{THY}^{-}$population than the SSEA $4^{+} /$Thy ${ }^{+}$population, providing further support for the presence of Sertoli cells (Fig. 3C). Lastly, VIM expression was significantly higher in the somatic SSEA4 ${ }^{-}$population in comparison with both SSEA4 ${ }^{+} /$ $\mathrm{THY}^{+}{ }^{+}$and SSEA4${ }^{+} \mathrm{THY}^{-}$population (Fig. $3 \mathrm{D}$ ).

After 32 weeks of gestation, all cells (gonocytes, prespermatogonia, and Sertoli cells) within the seminiferous cord continued to express SSEA4 (data not shown). The ratio of $\mathrm{VASA}_{\mathrm{D}} / \mathrm{VASA}_{\mathrm{B}}$ cells decreased to $<1 / 5$ when all $\mathrm{VASA}^{+}$cells from ten cords were counted, consistent with the continuous differentiation of gonocytes to prespermatogonia during fetal development (Fig. 4A). After the second trimester, THY1 expression was detected exclusively in somatic cells outside of the seminiferous cords (Fig. 4B), while KIT and OCT4A expression was no longer detected in either $V_{\mathrm{VASA}}$ or $\mathrm{VASA}_{\mathrm{B}}$ cells (data not shown).

\section{SSEA4 continues to be the membrane marker for SSCs postnatally}

Both SSCs and Sertoli cells from 4-month and 4-year-old boys continued to express SSEA4 within the seminiferous cord, similar to the fetal testes in the third trimester (Fig. 4C). Neither THY1 nor KIT expression was detected within the seminiferous cord of these prepubertal testes (data not shown). However, in contrast to the fetal testes, $<10 \%$ of spermatogonia were $V^{2} A_{D}$ postnatally (Fig. 4D).

When adult seminiferous tubules were examined, two populations of germ cells, VASA $\mathrm{D}$ and $\mathrm{VASA}_{\mathrm{B}}$, were also detected. VASA $A_{D}$ germ cells were seen in the basement membrane, where primitive spermatogonia and SSCs are located (Fig. 4E). In contrast, $\mathrm{VASA}_{B}$ germ cells were seen nearer toward the lumen consistent with mature spermatocytes. Interestingly, SSEA4 expression was detected only in $\mathrm{VASA}_{\mathrm{D}}$ germ cells, indicating that 
SSEA4 remained to be the membrane marker of primitive spermatogonia (Fig. 4E). Although THY1 expression had been found in early-fetal gonocytes, THY1 expression was restricted solely to somatic cells (Sertoli cells, peritubular interstitial cells, and cells making up the lamina propria) in adult men (Fig. 4F). Figure 5 shows the membrane markers of gonocytes and primitive spermatogonia (SSCs) during fetal and postnatal development.
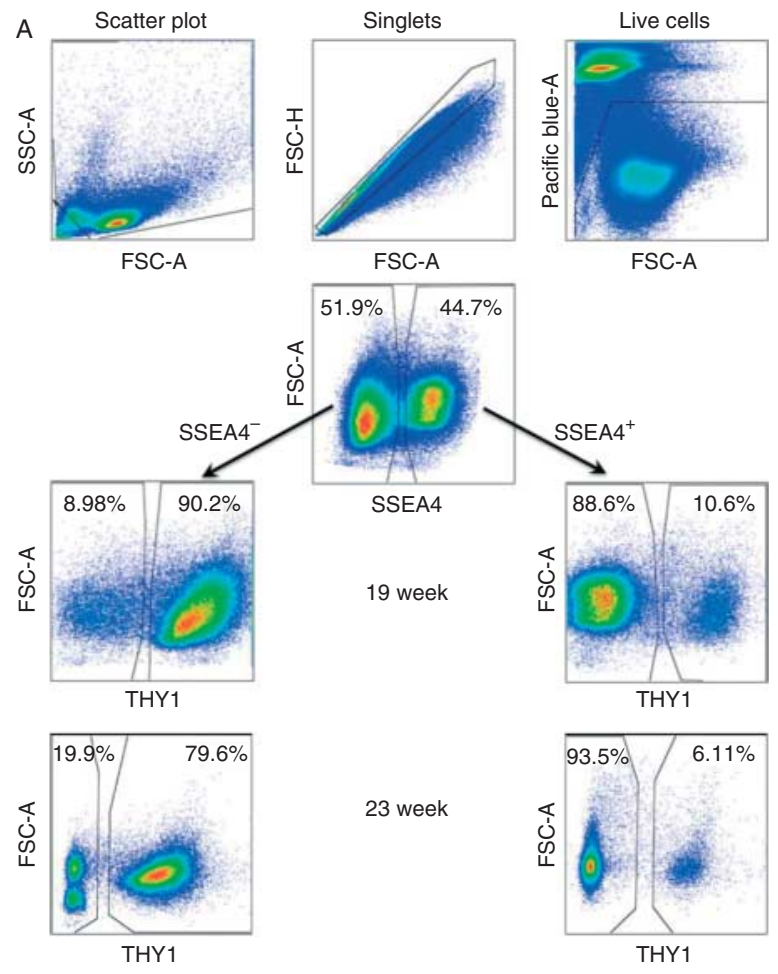

23 week

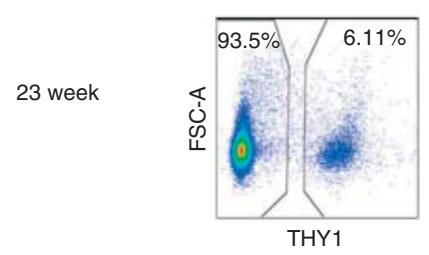

B
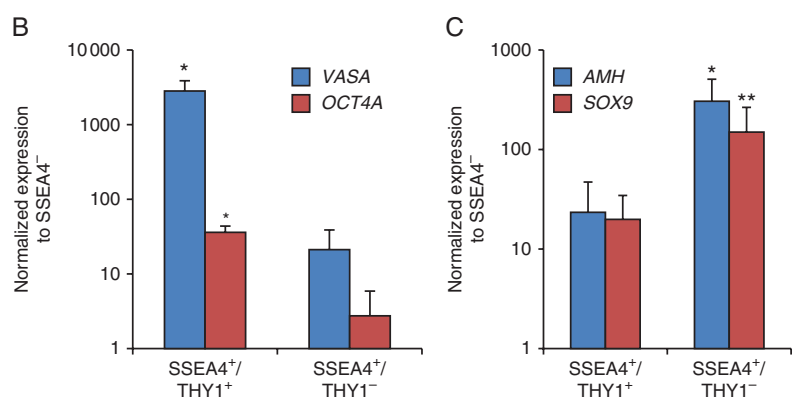

D

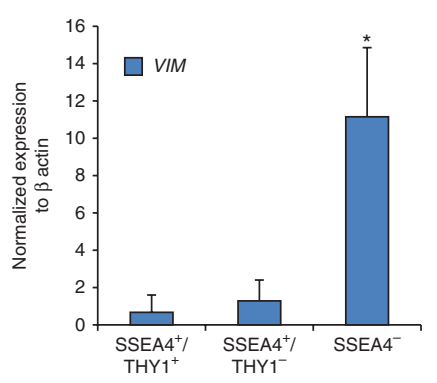

\section{Discussion}

We conducted a comprehensive in vitro characterization of germ cell membrane markers in human gonocytes, prespermatogonia, and SSCs from 13 weeks of gestation through adulthood. We report dynamic changes in the expression of known germ cell markers THY1, KIT, OCT4A, and VASA, and identified SSEA4 as a conserved extracellular membrane marker of male primitive germ cells during human male germ cell development.

In murine studies, VASA and OCT4 are co-expressed in primordial germ cells during their migration to the gonadal ridge (Fujiwara et al. 1994, Tanaka et al. 2000). Previous human studies reported that male germ cells do not express VASA until after 14 weeks of gestation (Anderson et al. 2007). Although OCT4A was described as the quintessential marker of human gonocytes during the first trimester, there was an uncoupling of OCT4Aexpressing gonocytes during the second trimester, as most gonocytes ceased to express OCT4A and differentiated into VASA expressing prespermatogonia (Pauls et al. 2006, Anderson et al. 2007). However, a recent study has demonstrated that human gonocytes co-expressed OCT4A, KIT, and VASA during the first trimester (7-11 weeks of gestation; Gkountela et al. 2012). Similarly, there was also an uncoupling of $\mathrm{OCT}_{4} \mathrm{~A}^{+} / \mathrm{KIT}^{+} / \mathrm{NASA}^{+}$gonocytes into $\mathrm{OCT} 4 \mathrm{~A}^{+} / \mathrm{KIT}^{+} /$ $\mathrm{VASA}^{-}$gonocytes and $\mathrm{OCT} 4 \mathrm{~A}^{-} / \mathrm{KIT}^{-} \mathrm{NASA}^{+}$prespermatogonia during the second trimester (Anderson et al. 2007, Gkountela et al. 2012). Due to limited sample availability, we focused our studies on male testes at 13 weeks of gestation and beyond. In the present study, we described VASA ${ }_{D}$ and $V A S A_{B}$ cells as two temporally and spatially distinct populations of germ cells that persisted through the second and third trimester. Our findings suggest a similar uncoupling of gonocytes and prespermatogonia to that previously reported in humans (Pauls et al. 2006, Anderson et al. 2007). While Gkountela and colleagues described two major distinct

Figure 3 Molecular analyses of fetal gonocytes, prespermatogonia and Sertoli cells. (A) SSEA4 and THY1 can be used as markers for separating gonocytes from prespermatogonia/Sertoli cells by FACS. Cellular debris clumps and dead cells were gated out before sorting. SSEA4 ${ }^{+}$and SSEA4 ${ }^{-}$cells were evaluated individually for THY1 expression. Consistent with confocal microscopy findings, the ratio of fetal gonocytes to prespermatogonia (VASA $/ V_{D} \mathrm{VAA}_{\mathrm{B}}$ ) declined with advancing gestation as demonstrated here between 19 and 23 weeks of gestation. (B) SSEA $4{ }^{+} / \mathrm{THY}^{+}{ }^{+}$cells (gonocytes) expressed $\mathrm{VASA}$ and OCT $4 A$ at significantly higher levels than SSEA $4^{+} / \mathrm{THY}^{-}$(prespermatogonia/Sertoli cells) cells. (C) SSEA $4^{+} / \mathrm{THY}^{-}{ }^{-}$cells expressed significantly higher levels of genes $(A M H)$ specific to Sertoli cells. SOX9 expression was not evaluated statistically for significance because only two biological samples were analyzed in the SSEA $4^{+} / \mathrm{THY}^{-}$ population. (D) Very low level of stromal marker VIM was detected in the SSEA $4{ }^{+}$populations. All qPCR reactions were ran in triplicates with three biological samples per group at 19 weeks of gestation except for one condition, in which only two biological samples were analyzed indicated as ${ }^{* *} .{ }^{*}$ statistical significant with $P<0.01$. 

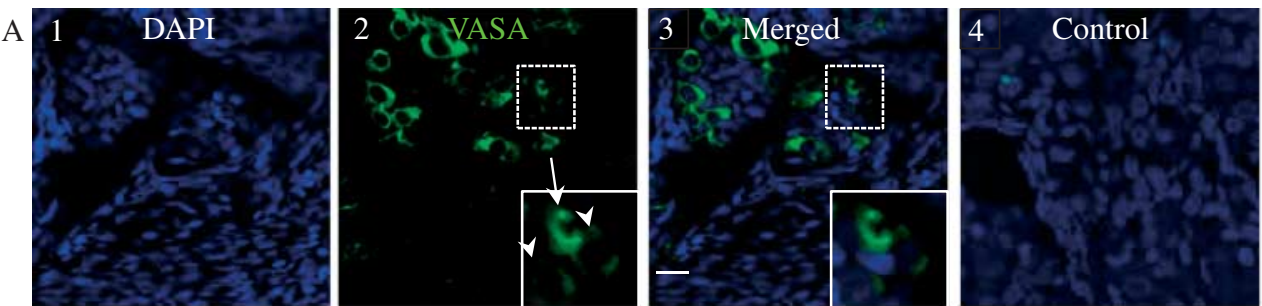

B
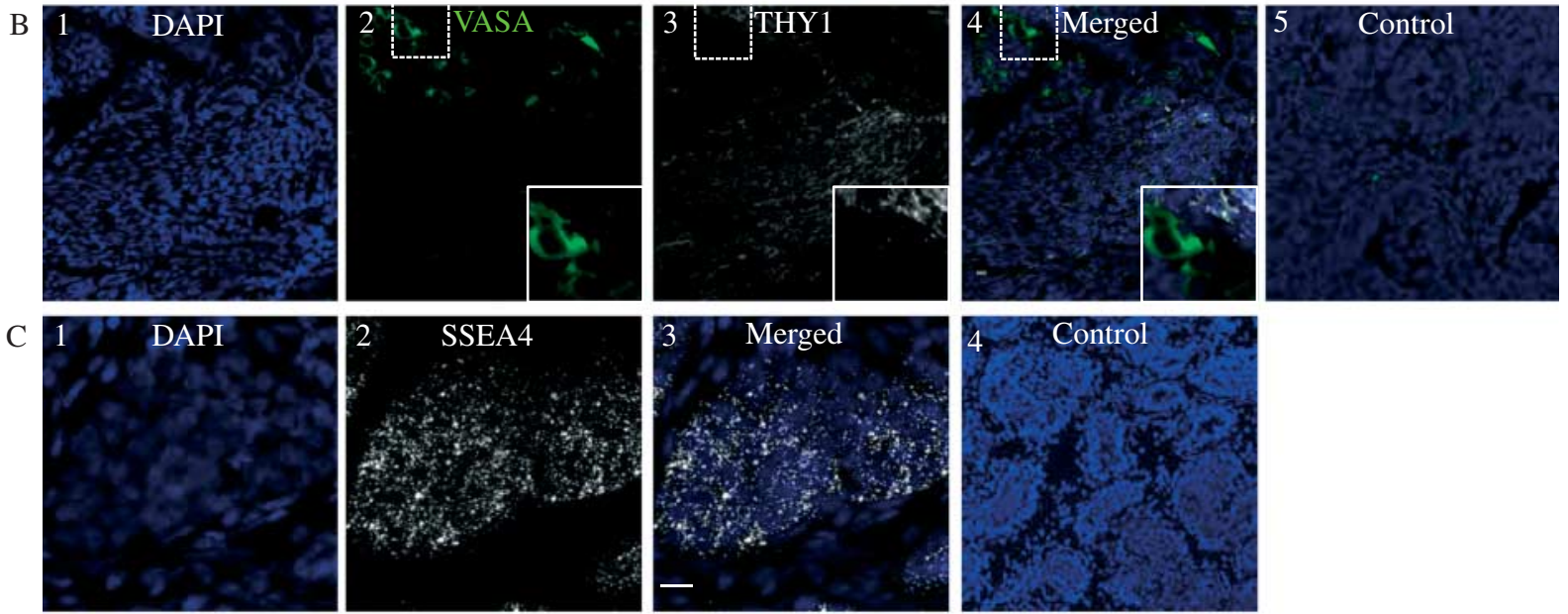

$\mathrm{D}$
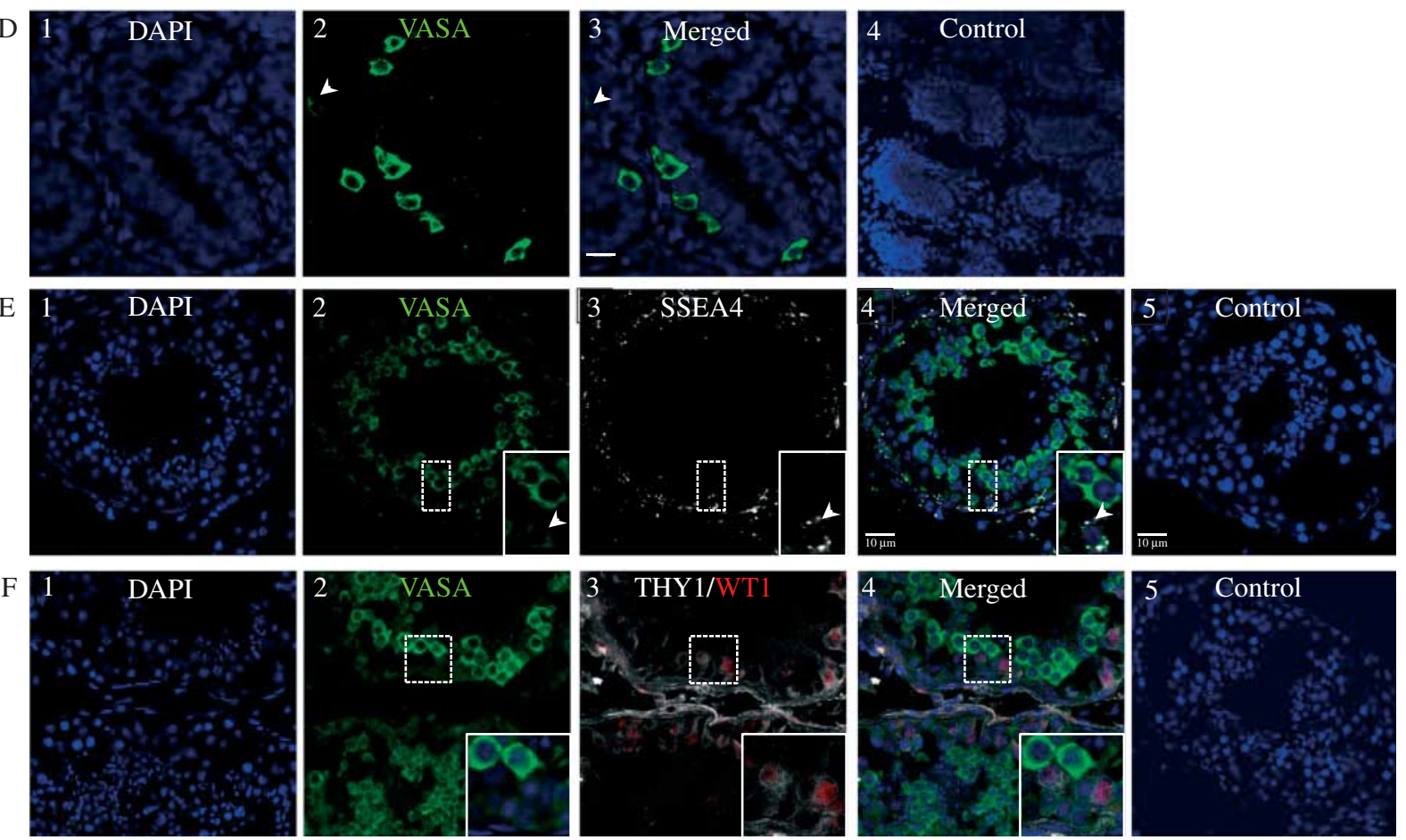

Figure 4 Changes in germ cell marker expression in the fetal testes after 24 weeks of gestation and after birth. (A) The number of gonocytes $\left(V A S A_{D}\right.$ cells) per testicular cord continued to decrease with advancing gestation. The ratio of VASA $/ \mathrm{VASA}_{\mathrm{B}}$ cells was $<20 \%$ at 32 weeks of gestation as shown here. (B) Although THY1 continued to be expressed in the somatic cells outside of the seminiferous cords, all germ cells ceased to express THY1, shown at 37 weeks of gestation. (C) In contrast, SSEA4 continued to be expressed in all cells within the seminiferous cord postnatally,

shown here at 4 years of age. (D) The ratio of $\mathrm{VASA}_{\mathrm{D}} / \mathrm{VASA}_{\mathrm{B}}$ germ cells $(<10 \%)$ continued to decline postnatally, shown here at 4 months of age. (E) Seminiferous tubules matured and formed lumen post pubertally as shown here from a normal adult sample. Primitive spermatogonia, located at the basement membrane, expressed low level of VASA (VASA $A_{D}$ ) whereas differentiating spermatocytes expressed high level of VASA (VASA ${ }_{B}$ ). While SSEA4 continued to be expressed in VASA ${ }_{D}$ spermatogonia, it was no longer expressed in Sertoli cells. (F) THY1 continued to be the marker of somatic cells within the seminiferous tubules. In addition, as Sertoli cells ceased to express SSEA4 after puberty, they began to express THY1 as shown with co-expression of WT1. Arrow heads and arrows indicate VASA ${ }_{D}$ and VASA $A_{B}$ cells respectively. Donkey anti-goat Alexa 488 (VASA), anti-rabbit Alexa 594 (WT1), and anti-mouse Alexa 555 (SSEA4) were used. 
populations of male human germ cells $\left(\mathrm{KIT}^{+} / \mathrm{NASA}^{-}\right.$ and $\mathrm{KIT}^{-} \mathrm{NASA}^{+}$) in second trimester testes, we did not detect any $\mathrm{KIT}^{+} / \mathrm{NASA}^{-}$gonocytes at any time points in our studies. As we used the same anti-VASA antibody, it is possible that differences in tissue processing and our use of confocal microscopy may account for the discrepancy in the relative detection of VASA expression between studies. Although none of the VASA ${ }_{B}$ germ cells in our study expressed markers associated with gonocytes (OCT4A and KIT), all VASA $\mathrm{D}_{\mathrm{D}}$ germ cells co-expressed both OCT4A and KIT, suggesting that they were the same population of primitive gonocytes previously reported (Pauls et al. 2006, Gkountela et al. 2012). Similar to the decline in $\mathrm{KIT}^{+}$and OCT4A ${ }^{+}$ gonocytes seen in previous studies, the number of $\mathrm{OCT}_{4} \mathrm{~A}^{+} / \mathrm{KIT}^{+} / \mathrm{NASA}_{\mathrm{D}}$ gonocytes also declined with advancing gestation in our studies (Pauls et al. 2006, Anderson et al. 2007, Gkountela et al. 2012).

Comprehensive screening of previously reported extracellular membrane markers of SSCs and embryonic stem cells revealed that KIT, THY1, and SSEA4 are the markers of human gonocytes. Specifically, KIT was found to be a transient marker of gonocytes during the second trimester; thereafter, its expression was not detected within the primitive germ cell compartment thereafter, consistent with previous human studies (Pauls et al. 2006, Gkountela et al. 2012). While THY1 was shown to be a marker of mouse SSCs, its role as marker of primate and adult human SSCs is controversial (Kubota et al. 2003, Conrad et al. 2008, Ko et al. 2010, 2011, Tapia et al. 2011, Chikhovskaya et al. 2012, Eildermann et al.
2012). We have recently demonstrated, using highly purified population of adult human testicular THY ${ }^{+}$ cells for analyses, that $\mathrm{THY}^{+}{ }^{+}$is a marker of adult testicular somatic cells, rather than SSCs which expressed SSEA4 (Smith et al. 2014). The findings of transient THY1 expression within the gonocyte population during the second trimester of gestation confirm that THY1 is not a marker of human SSCs postnatally (Ko et al. 2011, Tapia et al. 2011, Chikhovskaya et al. 2012, Smith et al. 2014).

SSEA4 is also a known marker of undifferentiated pluripotent human embryonic stem cells, cleavage to blastocyst stage embryos, and bone marrow-derived mesenchymal stem cells (Henderson et al. 2002, Rosu-Myles et al. 2013). Although associated with undifferentiated cells, the function of SSEA4 is currently unknown and remained to be investigated (Brimble et al. 2007). We demonstrated that SSEA4 was the common marker of human gonocytes, prespermatogonia, and primitive spermatogonia starting at 13 weeks of gestation through postpuberty, in contrast to the transient expression of THY1 and KIT seen in gonocytes. Although restricted to the seminiferous cord, SSEA4 expression was not exclusively expressed in the germ cell compartment within the fetal and prepubertal testes. In addition to gonocytes and prespermatogonia, SSEA4 was also found to be a marker of human Sertoli cells before puberty as demonstrated by confocal microscopy and confirmed by molecular analyses of subpopulations of SSEA4 expressing cells. However, there was a significant change in SSEA4 expression within the seminiferous

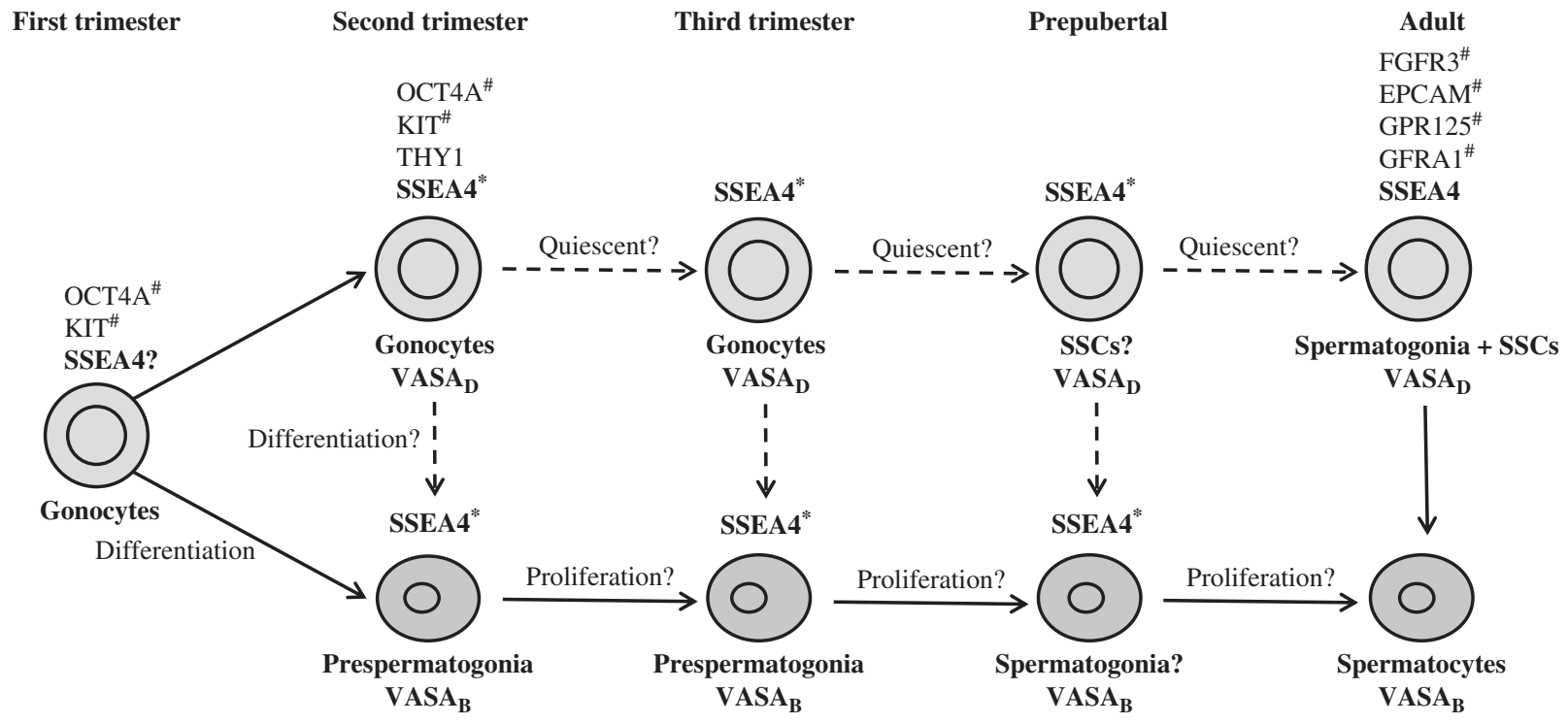

*Indicates also a marker of sertoli cells
\#Previously reported as markers of gonocytes and adult human SSCs. $_{\text {VASA }_{D} \text {, VASA dim; VASA }}$, VASA bright.

Figure 5 Markers of human gonocytes, prespermatogonia, and spermatogonia during development. 
tubules after puberty. Whereas SSEA4 expression continued to be restricted to the primitive spermatogonia in adult, Sertoli cells no longer expressed SSEA4. Our findings are consistent with recent reports that SSEA4 expression is restricted exclusively to primitive spermatogonia within the adult primate and human seminiferous tubules (Muller et al. 2008, Maki et al. 2009, Izadyar et al. 2011, Pacchiarotti et al. 2013). To assess the specificity of the SSEA4 antibody, we also evaluated for the expression of SSEA1 and SSEA3 by FACS and confocal microscopy and found that neither SSEA1 nor SSEA3 was expressed in human testicular tissues (data not shown), consistent with previous studies in primates (Muller et al. 2008).

SSEA4 is a conserved extracellular marker of primitive male human germ cells through all stages of development as described herein. Recent studies have also reported fibroblast growth factor receptor 3 (FGFR3) as a potential conserved membrane maker of human primitive spermatogonia (von Kopylow et al. 2010, 2012, Kossack et al. 2013). However, additional studies are still needed to further characterize this population (von Kopylow et al. 2010, 2012). In contrast to previous studies, we did not detect GPR125 and GFR 11 R expression in the fetal testes (Wu et al. 2009, He et al. 2010, Dovey et al. 2013). In addition, GPR125, GFR $\alpha 1 R$, and EPCAM expression does not appear to be specific to germ cells (Wu et al. 2009, He et al. 2010, Dovey et al. 2013). We recognize that GFR $1 R$ may be expressed in human fetal testes at a defined gestational window that we may not have evaluated, as mouse studies have demonstrated that Gfr 1 mRNA is detected in the testes up to dpc 14 and undetectable thereafter (Golden et al. 1999).

Recent studies have demonstrated that highly purified sorted adult human testicular SSEA $4^{+}$cells are germ cells that have not entered meiosis and can give rise to SSC colonies capable of expansion in vitro (Smith et al. 2014). Enriched adult testicular SSEA $4^{+}$cells were able to colonize mouse seminiferous tubules after transplantation confirming that the SSEA4 ${ }^{+}$population is highly enriched for SSCs (Izadyar et al. 2011). Thus, current evidence supports the use of SSEA4 as a membrane marker to isolate human primitive spermatogonia postnatally for in vitro expansion and differentiation. Currently, only one study demonstrated the ability to expand human SSCs in vitro by culture of unpurified prepubertal testicular tissue; however, the membrane markers of these prepubertal SSCs were not evaluated (Sadri-Ardekani et al. 2011).

In summary, we have described and characterized the dynamic changes in the expression of extracellular membrane markers of human male primitive germ cells from 13 weeks of gestation through adult. Specifically, SSEA4 was shown to be a unique ontogenically conserved marker of human spermatogonia through all stages of development. This finding contributes to the knowledge gap of identifying primitive spermatogonia for future transplantation studies.

\section{Supplementary data}

This is linked to the online version of the paper at http://dx.doi. org/10.1530/REP-14-0123.

\section{Declaration of interest}

The authors declare that there is no conflict of interest that could be perceived as prejudicing the impartiality of the research reported.

\section{Funding}

N D Tran is supported by ASRM new investigator award, UCSF Rap Grant, and Weston Haven Foundation.

\section{References}

Anderson RA, Fulton N, Cowan G, Coutts S \& Saunders PT 2007 Conserved and divergent patterns of expression of DAZL, VASA and OCT4 in the germ cells of the human fetal ovary and testis. BMC Developmental Biology 7 136. (doi:10.1186/1471-213X-7-136)

Brimble SN, Sherrer ES, Uhl EW, Wang E, Kelly S, Merrill AH Jr, Robins AJ \& Schulz TC 2007 The cell surface glycosphingolipids SSEA-3 and SSEA-4 are not essential for human ESC pluripotency. Stem Cells 25 54-62. (doi:10.1634/stemcells.2006-0232)

Brinster RL \& Avarbock MR 1994 Germline transmission of donor haplotype following spermatogonial transplantation. PNAS $\mathbf{9 1}$ 11303-11307. (doi:10.1073/pnas.91.24.11303)

Brinster RL \& Zimmermann JW 1994 Spermatogenesis following male germ-cell transplantation. PNAS 91 11298-11302. (doi:10.1073/pnas. 91.24.11298)

Cheng CY \& Mruk DD 2010 The biology of spermatogenesis: the past, present and future. Philosophical Transactions of the Royal Society of London. Series B, Biological Sciences 365 1459-1463. (doi:10.1098/ rstb.2010.0024)

Chikhovskaya JV, Jonker MJ, Meissner A, Breit TM, Repping S \& van Pelt AM 2012 Human testis-derived embryonic stem cell-like cells are not pluripotent, but possess potential of mesenchymal progenitors. Human Reproduction 27 210-221. (doi:10.1093/humrep/der383)

Conrad S, Renninger $M$, Hennenlotter J, Wiesner $T$, Just $L$, Bonin $M$, Aicher W, Buhring HJ, Mattheus U, Mack A et al. 2008 Generation of pluripotent stem cells from adult human testis. Nature 456 344-349. (doi:10.1038/nature07404)

Dovey SL, Valli H, Hermann BP, Sukhwani M, Donohue J, Castro CA, Chu T, Sanfilippo JS \& Orwig KE 2013 Eliminating malignant contamination from therapeutic human spermatogonial stem cells. Journal of Clinical Investigation 123 1833-1843. (doi:10.1172/ JCl65822)

Dym M, Kokkinaki M \& He Z 2009 Spermatogonial stem cells: mouse and human comparisons. Birth Defects Research. Part C, Embryo Today: Reviews 87 27-34. (doi:10.1002/bdrc.20141)

Ebata KT, Zhang X \& Nagano MC 2005 Expression patterns of cell-surface molecules on male germ line stem cells during postnatal mouse development. Molecular Reproduction and Development 72 171-181. (doi:10.1002/mrd.20324)

Eildermann K, Gromoll J \& Behr R 2012 Misleading and reliable markers to differentiate between primate testis-derived multipotent stromal cells and spermatogonia in culture. Human Reproduction 27 1754-1767. (doi:10.1093/humrep/des091) 
Fujita K, Ohta H, Tsujimura A, Takao T, Miyagawa Y, Takada S, Matsumiya K, Wakayama T \& Okuyama A 2005 Transplantation of spermatogonial stem cells isolated from leukemic mice restores fertility without inducing leukemia. Journal of Clinical Investigation $\mathbf{1 1 5}$ 1855-1861. (doi:10.1172/JCl24189)

Fujita K, Tsujimura A, Miyagawa Y, Kiuchi H, Matsuoka Y, Takao T, Takada S, Nonomura N \& Okuyama A 2006 Isolation of germ cells from leukemia and lymphoma cells in a human in vitro model: potential clinical application for restoring human fertility after anticancer therapy. Cancer Research 66 11166-11171. (doi:10.1158/0008-5472. CAN-06-2326)

Fujiwara $Y$, Komiya T, Kawabata H, Sato M, Fujimoto H, Furusawa M \& Noce T 1994 Isolation of a DEAD-family protein gene that encodes a murine homolog of Drosophila vasa and its specific expression in germ cell lineage. PNAS 91 12258-12262. (doi:10.1073/ pnas.91.25.12258)

Gashaw I, Dushaj O, Behr R, Biermann K, Brehm R, Rubben H, Grobholz R, Schmid KW, Bergmann M \& Winterhager E 2007 Novel germ cell markers characterize testicular seminoma and fetal testis. Molecular Human Reproduction 13 721-727. (doi:10.1093/molehr/ gam059)

Gkountela S, Li Z, Vincent JJ, Zhang KX, Chen A, Pellegrini M \& Clark AT 2012 The ontogeny of $\mathrm{CKIT}^{+}$human primordial germ cells proves to be a resource for human germ line reprogramming, imprint erasure and in vitro differentiation. Nature Cell Biology 15 113-122. (doi:10.1038/ ncb2638)

Golden JP, DeMaro JA, Osborne PA, Milbrandt J \& Johnson EM Jr 1999 Expression of neurturin, GDNF, and GDNF family-receptor mRNA in the developing and mature mouse. Experimental Neurology 158 504-528. (doi:10.1006/exnr.1999.7127)

Golestaneh N, Kokkinaki M, Pant D, Jiang J, DeStefano D, FernandezBueno C, Rone JD, Haddad BR, Gallicano GI \& Dym M 2009 Pluripotent stem cells derived from adult human testes. Stem Cells and Development 18 1115-1126. (doi:10.1089/scd.2008.0347)

Grisanti L, Falciatori I, Grasso M, Dovere L, Fera S, Muciaccia B, Fuso A, Berno V, Boitani C, Stefanini M et al. 2009 Identification of spermatogonial stem cell subsets by morphological analysis and prospective isolation. Stem Cells 27 3043-3052. (doi:10.1002/stem.206)

He Z, Kokkinaki M, Jiang J, Dobrinski I \& Dym M 2010 Isolation, characterization, and culture of human spermatogonia. Biology of Reproduction 82 363-372. (doi:10.1095/biolreprod.109.078550)

Henderson JK, Draper JS, Baillie HS, Fishel S, Thomson JA, Moore H \& Andrews PW 2002 Preimplantation human embryos and embryonic stem cells show comparable expression of stage-specific embryonic antigens. Stem Cells 20 329-337. (doi:10.1634/stemcells.20-4-329)

Hermann BP, Sukhwani M, Salati J, Sheng Y, Chu T \& Orwig KE 2011 Separating spermatogonia from cancer cells in contaminated prepubertal primate testis cell suspensions. Human Reproduction 26 3222-3231. (doi:10.1093/humrep/der343)

Izadyar F, Wong J, Maki C, Pacchiarotti J, Ramos T, Howerton K, Yuen C, Greilach S, Zhao HH, Chow M et al. 2011 Identification and characterization of repopulating spermatogonial stem cells from the adult human testis. Human Reproduction 26 1296-1306. (doi:10.1093/ humrep/der026)

Jorgensen A, Nielsen JE, Jensen MB, Graem N \& Rajpert-De Meyts E 2012 Analysis of meiosis regulators in human gonads: a sexually dimorphic spatio-temporal expression pattern suggests involvement of DMRT1 in meiotic entry. Molecular Human Reproduction 18 523-534. (doi:10. 1093/molehr/gas030)

Kanatsu-Shinohara M, Ogonuki N, Inoue K, Miki H, Ogura A, Toyokuni S \& Shinohara T 2003 Long-term proliferation in culture and germline transmission of mouse male germline stem cells. Biology of Reproduction 69 612-616. (doi:10.1095/biolreprod.103.017012)

Ko K, Arauzo-Bravo MJ, Tapia N, Kim J, Lin Q, Bernemann C, Han DW, Gentile L, Reinhardt P, Greber B et al. 2010 Human adult germline stem cells in question. Nature 465 E1; discussion E3. (doi:10.1038/ nature09089)

Ko K, Reinhardt P, Tapia N, Schneider RK, Arauzo-Bravo MJ, Han DW, Greber B, Kim J, Kliesch S, Zenke M et al. 2011 Brief report: evaluating the potential of putative pluripotent cells derived from human testis. Stem Cells 29 1304-1309. (doi:10.1002/stem.671) von Kopylow K, Kirchhoff C, Jezek D, Schulze W, Feig C, Primig M, Steinkraus V \& Spiess AN 2010 Screening for biomarkers of spermatogonia within the human testis: a whole genome approach. Human Reproduction 25 1104-1112. (doi:10.1093/humrep/ deq053)

von Kopylow K, Staege H, Schulze W, Will H \& Kirchhoff C 2012 Fibroblast growth factor receptor 3 is highly expressed in rarely dividing human type A spermatogonia. Histochemistry and Cell Biology 138 759-772. (doi:10.1007/s00418-012-0991-7)

Kossack N, Meneses J, Shefi S, Nguyen HN, Chavez S, Nicholas C, Gromoll J, Turek PJ \& Reijo-Pera RA 2009 Isolation and characterization of pluripotent human spermatogonial stem cell-derived cells. Stem Cells 27 138-149. (doi:10.1634/stemcells. 2008-0439)

Kossack N, Terwort N, Wistuba J, Ehmcke J, Schlatt S, Scholer H, Kliesch S \& Gromoll JA 2013 A combined approach facilitates the reliable detection of human spermatogonia in vitro. Human Reproduction $\mathbf{2 8}$ 3012-3025. (doi:10.1093/humrep/det336)

Kubota H, Avarbock MR \& Brinster RL 2003 Spermatogonial stem cells share some, but not all, phenotypic and functional characteristics with other stem cells. PNAS 100 6487-6492. (doi:10.1073/pnas. 0631767100)

Liu S, Tang Z, Xiong T \& Tang W 2011 Isolation and characterization of human spermatogonial stem cells. Reproductive Biology and Endocrinology 9 141. (doi:10.1186/1477-7827-9-141)

Maki CB, Pacchiarotti J, Ramos T, Pascual M, Pham J, Kinjo J, Anorve S \& Izadyar F 2009 Phenotypic and molecular characterization of spermatogonial stem cells in adult primate testes. Human Reproduction 24 1480-1491. (doi:10.1093/humrep/dep033)

Mirzapour T, Movahedin M, Tengku Ibrahim TA, Koruji M, Haron AW, Nowroozi MR \& Rafieian SH 2012 Effects of basic fibroblast growth factor and leukaemia inhibitory factor on proliferation and short-term culture of human spermatogonial stem cells. Andrologia $\mathbf{4 4}$ 41-55. (doi:10.1111/j.1439-0272.2010.01135.x)

Mizrak SC, Chikhovskaya JV, Sadri-Ardekani H, van Daalen S, Korver CM, Hovingh SE, Roepers-Gajadien HL, Raya A, Fluiter K, de Reijke TM et al. 2010 Embryonic stem cell-like cells derived from adult human testis. Human Reproduction 25 158-167. (doi:10.1093/humrep/ dep354)

Muller T, Eildermann K, Dhir R, Schlatt S \& Behr R 2008 Glycan stem-cell markers are specifically expressed by spermatogonia in the adult non-human primate testis. Human Reproduction 23 2292-2298. (doi:10.1093/humrep/den253)

Pacchiarotti J, Ramos T, Howerton K, Greilach S, Zaragoza K \& Olmstead M 2013 Developing a clinical-grade cryopreservation protocol for human testicular tissue and cells. BioMed Research International 2013 10. (doi:10.1155/2013/930962)

Pauls K, Schorle H, Jeske W, Brehm R, Steger K, Wernert N, Buttner R \& Zhou H 2006 Spatial expression of germ cell markers during maturation of human fetal male gonads: an immunohistochemical study. Human Reproduction 21 397-404. (doi:10.1093/ humrep/dei325)

Rosu-Myles M, McCully J, Fair J, Mehic J, Menendez P, Rodriguez R \& Westwood C 2013 The globoseries glycosphingolipid SSEA-4 is a marker of bone marrow-derived clonal multipotent stromal cells in vitro and in vivo. Stem Cells and Development 22 1387-1397. (doi:10.1089/ scd.2012.0547)

Sadri-Ardekani H, Mizrak SC, van Daalen SK, Korver CM, RoepersGajadien HL, Koruji M, Hovingh S, de Reijke TM, de la Rosette JJ, van der Veen $\mathbf{F}$ et al. 2009 Propagation of human spermatogonial stem cells in vitro. Journal of the American Medical Association 302 2127-2134. (doi:10.1001/jama.2009.1689)

Sadri-Ardekani H, Akhondi MA, van der Veen F, Repping S \& van Pelt AM 2011 In vitro propagation of human prepubertal spermatogonial stem cells. Journal of the American Medical Association 305 2416-2418. (doi:10.1001/jama.2011.791)

Seandel M, James D, Shmelkov SV, Falciatori I, Kim J, Chavala S, Scherr DS, Zhang F, Torres R, Gale NW et al. 2007 Generation of functional multipotent adult stem cells from GPR $125^{+}$germline progenitors. Nature 449 346-350. (doi:10.1038/nature06129) 
Smith JF, Yango P, Altman E, Choudhry S, Poelzl A, Zamah AM, Rosen M, Klatsky PC \& Tran ND 2014 Testicular Niche Required for Human Spermatogonial Stem Cell Expansion. Stem Cells Translational Medicine. In Press. (doi:10.5966/sctm.2014-0045)

Tanaka SS, Toyooka Y, Akasu R, Katoh-Fukui Y, Nakahara Y, Suzuki R, Yokoyama M \& Noce T 2000 The mouse homolog of Drosophila Vasa is required for the development of male germ cells. Genes and Development 14 841-853. (doi:10.1101/gad.14.7.841)

Tapia N, Arauzo-Bravo MJ, Ko K \& Scholer HR 2011 Concise review: challenging the pluripotency of human testis-derived ESC-like cells. Stem Cells 29 1165-1169. (doi:10.1002/stem.669)
Wu X, Schmidt JA, Avarbock MR, Tobias JW, Carlson CA, Kolon TF, Ginsberg JP \& Brinster RL 2009 Prepubertal human spermatogonia and mouse gonocytes share conserved gene expression of germline stem cell regulatory molecules. PNAS 106 21672-21677. (doi:10.1073/pnas.0912432106)

Received 3 March 2014

First decision 24 March 2014

Revised manuscript received 30 June 2014

Accepted 15 July 2014 